\title{
Proposing a set of ethical guidelines for Iranian physiotherapists: results of a modified Delphi technique
}

\author{
MARZIEH MOHAMADI, ZAHRA ROJHANI-SHIRAZI, SEYED ALI ENJOO, EHSAN SHAMSI-GOOSHKI, IRAJ ABDOLLAHI, FATEMEH BAHMANI, MOHSEN \\ RAZEGHI
}

\begin{abstract}
The code of ethical conduct for physiotherapy services must be compatible with the local culture. The ethical guidelines proposed here were developed through a literature review, focus group discussions, and finally a modified Delphi technique to achieve consensus after the data were analysed. At first, the collection of different ethical codes yielded 132 items. In the second stage, repetitive items were discarded, some new items were added, and the various codes were categorised into three domains. Overall, 175 items were considered in the Delphi stage. Subsequently, the items were reduced to 134 in total - 59 in the treatment domain, 41 in research, and 34 in the education domain. The resulting code of ethics will support patients, researchers, students, and teachers in the field of physical therapy with sensitivity to current Iranian legislation and culture.
\end{abstract}

Keywords: Ethics, physiotherapy, physical therapy.

\section{Introduction}

Codes of conduct and ethical requirements are common

Authors: Marzieh Mohamadi (mohamadipt@yahoo.com), Department of Physical Therapy, School of Rehabilitation Sciences, Shiraz University of Medical Sciences, Shiraz, Iran; Zahra Rojhani-Shirazi (rojhaniz@sums.ac.ir), Department of Physical Therapy, School of Rehabilitation Sciences, Shiraz University of Medical Sciences, Shiraz, Iran; Seyed Ali Enjoo (corresponding author: seyed.ali.enjoo@gmail.com), Department of Medical Ethics, School of Traditional Medicine, Shahid Beheshti University of Medical Sciences, Tehran, Iran; Ehsan ShamsiGooshki (shamsi@tums.ac.ir), Assistant Professor of Medical Ethics, Medical Ethics and History of Medicine Research Center and Faculty of Medicine, Tehran University of Medical Sciences, Tehran; Iraj Abdollahi (irajabdollahi@hotmail.com), Department of Physical Therapy, University of Social Welfare and Rehabilitation Sciences, Tehran, Iran; Fatemeh Bahmani (fbahmanimd@gmail.com), Department of Medical Ethics, School of Medicine, Iran University of Medical Sciences, Tehran, Iran; Mohsen Razeghi (razeghm@sums.ac.ir), Department of Physical Therapy, School of Rehabilitation Sciences, Shiraz University of Medical Sciences, Shiraz, Iran.

To cite: Mohamadi M, Rojhani-Shirazi Z, Enjoo SA, Shamsi-Gooshki E, Abdollahi I, Bahmani F, Razeghi M. Proposing a set of ethical guidelines for Iranian physiotherapists: Result of a modified Delphi technique. Published online first on May 13, 2021.DOI: 10.20529/IJME.2021.035.

Manuscript Editor:Vijayaprasad Gopichandran

Peer Reviewers: Aarthi Raveendiran, Aarthy Ramaswamy

C Indian Journal of Medical Ethics 2021 ways to advance professional integrity in a professional area, consolidated by guidelines and regulations (1: pp. 19). Physiotherapists must frequently make decisions involving ethical considerations. Thus, an ethical framework would enable greater independence and autonomy in decisionmaking among physiotherapists, providing them the necessary context and vocabulary (2).

Between 1970 and 2000, two different approaches emerged to define ethical frameworks in the context of physiotherapy around the world. The first, an essentially philosophical approach, concerned how physiotherapists should conduct their professional activities. Later, biomedical values were posited as a basis for ethical behaviour. A more in-depth look at the literature suggests that broadly, between 1970 and 1979, physiotherapists were viewed as decision-makers. They used to work under the supervision of physicians; Specialisation for physical therapy occurred in 1974. In the following decade, from 1980 to 1989, philosophical principles were applied to physiotherapy; and between 1990 and 2000, the relationship between physiotherapists and patients received increasing attention (3). Philosophical ethics is concerned with what people ought to do and how they ought to conduct themselves, as well as the rational basis for these types of decisions. The goal of philosophical ethics is to advise action, to shed light on what "ought" to happen (4). Between 2000 and 2007, a focus on ethical issues emphasised the link between theory and practice in clinical physiotherapy (3).

Since 1935, national and international associations have developed specific codes of ethics for physiotherapy (5). The American Physical Therapy Association (APTA) proposed 8 principles, including 38 ethical recommendations, in an effort to create a foundation for integrity of practice among its members (6). Similarly, the Australian Physiotherapy Association (APA) sought to provide ethical physiotherapy services for all Australians by establishing 9 principles and 59 recommendations for professional conduct (7), and the World Confederation for Physical Therapy (WCPT or, more commonly, World Physiotherapy) currently expects physiotherapists to abide by 8 principles and 40 recommendations of good practice (8).

It has been suggested that the societal dimensions of ethical obligations affect codes of ethics in different societies (5). In addition, cultural diversity in how services are framed and 
received is a key factor in the healthcare professions (9). Previous studies suggest that physiotherapists should modify their approach so that it becomes "compatible with clienteles' culturally-diverse needs" (10-12). This approach would ensure that medical services are appropriate to that culture.

In Iran, because of local considerations, including the predominantly Muslim population of the country, physiotherapy services and consequently codes of ethical conduct must be compatible not only with the best medical and healthcare practices, but also with Islamic culture and Persian civilisation. Unfortunately, a national consensus on best practices for physical therapists is yet to emerge. Within the nationwide plan called packages for reform and innovation in medical sciences education started in the spring of 2015, the task of developing a territorial health plan was assigned to the authors of the present article. Because of the importance of achieving consensus, and in order to incorporate the most effective practical features into the national code of conduct for physiotherapists in Iran, we decided to use a modified Delphi technique to develop these ethical guidelines.

\section{Methodology}

The core members of the research team consisted of physiotherapy and medical ethics specialists and faculty members. Once the project design was finalised, the steps described below were undertaken.

\section{Advanced literature review}

The first stage of the study consisted of a literature review of both healthcare ethics and the rehabilitation profession to develop a commonly understandable terminology. The authors then studied and discussed similar national guidelines from around the world to identify simple, independent concepts across the relevant documents. This also allowed the authors to identify the documents and concepts that could potentially be applied to Iranian culture and society. Five meetings were held at the dean's office of the School of Rehabilitation Sciences, Shiraz University of Medical Sciences. At these meetings, a nominal group technique was used to brainstorm and develop a tentative draft, reflecting the goals for the final set of guidelines. The meetings took place around a round table, and each expert was asked to contribute her or his five most relevant articles. Duplicate recommendations were counted only once.

\section{Focus group discussion}

In the second stage, the results of the literature review were classified, and the initial draft of the guidelines was validated through smaller focus group discussions.

A panel of experts was invited to participate. This group consisted of three faculty members from the physiotherapy department and two faculty members from the medical ethics department. They were selected because of their experience working in the field of the ethics of physical therapy. Over the course of nine meetings, the items in the initial draft were discussed, and the most suitable terms in Persian were chosen by $100 \%$ consensus among the participants. These meetings were held between January and March 2016, around a square table in the office of the deputy dean. Each meeting lasted for three hours or longer. Finally, the results from these expert consultations were categorised into the treatment, research, and education domains, and the next draft of guidelines was prepared for the next stage, which was to achieve nationwide consensus using the Delphi technique.

\section{Modified Delphi technique to achieve consensus}

In the third stage, a broader range of participants were invited to take part, using the modified Delphi technique, with a goal of reaching at least $75 \%$ consensus (13). The participants consisted of members of the focus discussion group plus six expert faculty members from the physiotherapy departments of rehabilitation schools at universities around the country. For this stage. a questionnaire and a five-point Likert scale were prepared. The questionnaire consisted of open-ended questions, and the instrument requested feedback on a total of 175 items across the three different domains. In the first Delphi round, the questionnaire was sent to 11 participants by email. The participants were asked to score each item from 1 (lowest) to 5 (highest). Space for additional comments and explanations was provided to make the questionnaire semiopen and to allow respondents to elaborate on and clarify their opinions regarding each item in the draft guidelines, as well as to allow them to raise new questions.

In the second Delphi round, items with less than $75 \%$ consensus and the comments from the respondents were sent to the participants for scoring again and review. Participants were invited to elaborate on their reasons in writing, and were given time to discuss the comments.

In the third Delphi round, participants were allowed to change their responses or provide additional comments in support of their stance. Finally, the data were analysed and the final version of the code of ethical conduct for physiotherapists was generated.

\section{Results}

Demographic information for participants from the schools of rehabilitation sciences and departments of medical ethics at different medical universities are presented in Table 1.

The literature review and collection of different codes of ethical conduct in the first stage of the study yielded three main domains and several subdomains (Table 2) and a total of 132 potential items. In the second stage of the study, duplicate items were discarded, some new items were added, and all items were categorised into three domains, ie, treatment (41 items), research (67 items), and education (67 items). In all, 175 items entered the Delphi technique stage. 
Ten out of 11 participants in the third stage (Delphi technique) completed the study. During the Delphi technique phase, 20 items were added in the treatment domain, 2 items were deleted, and 9 were changed. In the research domain, 3 items were added, 29 were deleted, and 4 were changed. In the education domain, 5 items were added, 38 were deleted, and 30 were changed. Subsequently, the total number of items was reduced to 134:59 in the treatment domain, 41 in the research domain, and 34 in the education domain (Table 3). The full version of the developed guidelines in Persian is available on our website*. All final items in the code of conduct were accepted by consensus among more than $75 \%$ of all the experts consulted.

Table 1: Demographic information on participants in the modified Delphi technique

\begin{tabular}{|c|c|c|c|c|c|c|}
\hline & \multicolumn{2}{|c|}{ Advanced literature review stage $(n=9)$} & \multicolumn{2}{|c|}{ Focus group discussion stage $(n=5)$} & \multicolumn{2}{|c|}{ Modified Delphi technique stage $(n=10)$} \\
\hline & Frequency & Percentage & Frequency & Percentage & Frequency & Percentage \\
\hline Age in years & & & & & & \\
\hline $31-40$ & 3 & 33.3 & 3 & 60 & 4 & 40 \\
\hline $41-50$ & 4 & 44.4 & 0 & 0 & 4 & 40 \\
\hline $51-60$ & 2 & 22.2 & 2 & 40 & 2 & 20 \\
\hline$>60$ & 0 & 0 & 0 & 0 & 0 & 0 \\
\hline$\underline{\underline{\text { Sex }}}$ & & & & & & \\
\hline Female & 3 & 33.3 & 2 & 40 & 2 & 20 \\
\hline Male & 6 & 66.6 & 3 & 60 & 8 & 80 \\
\hline \begin{tabular}{|l|} 
Professional \\
practice
\end{tabular} & & & & & & \\
\hline Rehabilitation & 9 & 100 & 3 & 60 & 8 & 80 \\
\hline Physician & 0 & 0 & 2 & 40 & 2 & 20 \\
\hline Medical ethics & 0 & 0 & 2 & 40 & 2 & 20 \\
\hline $\begin{array}{l}\text { Years of } \\
\text { professional } \\
\text { practice }\end{array}$ & & & & & & \\
\hline$\geq 10$ & 2 & 22.2 & 2 & 40 & 3 & 30 \\
\hline $11-20$ & 4 & 44.4 & 1 & 20 & 2 & 20 \\
\hline $21-30$ & 3 & 33.3 & 2 & 40 & 5 & 50 \\
\hline$>30$ & 0 & 0 & 0 & 0 & 0 & 0 \\
\hline $\begin{array}{l}\text { Years of } \\
\text { practice as } \\
\text { medical } \\
\text { ethics } \\
\text { activist }\end{array}$ & & & & & & \\
\hline$\geq 5$ & $5 *$ & 55.5 & $1 *$ & 20 & $4^{*}$ & 40 \\
\hline $6-10$ & $3^{*}$ & 33.3 & 1 & 20 & $2\left(1+1^{*}\right)$ & 20 \\
\hline $11-20$ & $1^{*}$ & 11.1 & $3(1+2 *)$ & 60 & $4(1+3 *)$ & 40 \\
\hline $21-30$ & 0 & 0 & 0 & 0 & 0 & 0 \\
\hline \begin{tabular}{|l} 
Academic \\
position
\end{tabular} & & & & & & \\
\hline Full professor & 0 & 0 & 0 & 0 & 0 & 0 \\
\hline $\begin{array}{l}\text { Associate } \\
\text { professor }\end{array}$ & 2 & 22.2 & 2 & 40 & 4 & 40 \\
\hline $\begin{array}{l}\text { Assistant } \\
\text { professor }\end{array}$ & 6 & 66.6 & 2 & 40 & 5 & 50 \\
\hline $\begin{array}{l}\text { PhD } \\
\text { candidate }\end{array}$ & 1 & 11.1 & 1 & 20 & 1 & 10 \\
\hline
\end{tabular}


Table 2: Ethical considerations identified with the Delphi technique

\begin{tabular}{|c|}
\hline Section 1: Ethics in providing physiotherapy services \\
\hline Chapter 1: Respect for patient rights and human dignity \\
\hline $\begin{array}{l}\text { Axis 1: Providing high-quality care based on scientific } \\
\text { standards }\end{array}$ \\
\hline $\begin{array}{l}\text { Axis 2: Respect for patients' privacy, confidentiality, and } \\
\text { preferences }\end{array}$ \\
\hline Axis 3: Honesty and veracity \\
\hline Axis 4: Compassion and empathy \\
\hline Chapter 2: Equity and justice \\
\hline Chapter 3: Primacy of patient interest and non-maleficence \\
\hline Chapter 4: Social responsibility of professionals \\
\hline Chapter 5: Ethics in professional relations \\
\hline Chapter 6: Compliance with social norms and regulatory laws \\
\hline Section 2: Research ethics in physiotherapy \\
\hline $\begin{array}{l}\text { Chapter 1:General considerations; contribution to research, } \\
\text { planning, and promotion of the profession }\end{array}$ \\
\hline Chapter 2: Specific considerations in different stages of research \\
\hline Axis 1: Before conducting the research \\
\hline Axis 2: While conducting the research \\
\hline Axis 3: After conducting the research \\
\hline Section 3: Ethics in physiotherapy education \\
\hline Chapter 1: The ethics guide to student education \\
\hline $\begin{array}{l}\text { Axis 1: Demonstrated efforts towards the advancement of } \\
\text { students' knowledge }\end{array}$ \\
\hline Axis 2: Ethical guidelines for clinical education \\
\hline Axis 3: Adherence to social and cultural norms \\
\hline $\begin{array}{l}\text { Chapter 2: The ethics guide to respecting the rights of colleagues, } \\
\text { institutions, and professionals }\end{array}$ \\
\hline Chapter 3: Ethics guide for students \\
\hline Axis 1: Striving for the proper use of knowledge \\
\hline Axis 2: Ethical guidelines for clinical education for students \\
\hline Axis 3: Adherence to social and cultural norms \\
\hline
\end{tabular}

\section{Table 3: The detailed codes}

\begin{tabular}{|l|}
\hline A Guide to Professional Conduct in Physiotherapy \\
\hline Preamble \\
\hline $\begin{array}{l}\text { Today, science is advancing at a remarkable rate. However, scientific } \\
\text { advances will benefit human beings if they are morally supported. This } \\
\text { is the case with all sciences, including medical sciences. In fact, ethics } \\
\text { plays a pivotal role in medicine. }\end{array}$ \\
\hline
\end{tabular}

Physiotherapy is one of the fields of medical science that have grown significantly in recent years. Evaluation, diagnosis, and treatment of a wide range of disorders and diseases are offered in physiotherapy. Non-compliance with ethical principles limits physiotherapists' clinical practice and can harm patients. This code of ethics has been designed and introduced in order to surmount such limitations and prevent resultant harms. Ethical agencies in physiotherapy around the world have provided similar ethical codes.

It is not possible to develop medical codes of ethics without considering the beliefs, values, and moral principles of the affected society. Iran's governmental policies in the field of health emphasise a core of morality, aligned with the Iranian Constitution and the Article 1 of the Civil Law of the Islamic Republic of Iran which give priority to ethico-islamic principles. the Islamic Republicof Iran has also developed and publicised various ethical guidelines, including the General Guide to Professional Ethics for Professionals Affiliate with the Medical Council of the Islamic Republic of Iran, as well as general and specific national biomedical research ethical guidelines, which implies the importance of prosessional ethics in the Iranian society. Given that the purpose of such moral centredness is to uphold standards in the fields of medical treatment, research, and education, the first step to achieve this goal is to establish clear guidelines. Therefore, there is a need to establish a code of ethics for physiotherapy for professionals, researchers, professors, and students.

This research has been undertaken using a methodological and scientific approach in line with previous attempts to compile codes of ethics for physiotherapy, and it is hoped that it will complement the previous efforts of researchers in this field. The principles presented in this research have been drafted according to international codes and keeping in mind the cultural, social, and ideological concerns of Iranian society. These principles are structured in three sections: 'Ethics in providing physiotherapy services', 'Research ethics in physiotherapy', and 'Ethics in physiotherapy education'. Each section has various chapters and axes, covering the pertinent codes of ethics.

These ethical guidelines are recommended for implementation to the competent authorities, including professional institutions, and also the relevant organisations.

\section{Section 1: Ethics in providing physiotherapy services}

Chapter 1: Respect for patient rights and human dignity

Axis 1:Providinghigh-quality care based on scientific standards

1.1.1. Professionals are obliged to provide appropriate and decent patient care.

1.1.2. Professionals shall be aware of and practice in accordance with the latest technical and scientific standards of the profession.

1.1.3. Professionals are obliged to follow nationally approved diagnostic and treatment guidelines to the extent feasible.

1.1.4. Professionals must provide merely those services that they have received relevant training in and of which they possess sufficient knowledge, skills, and experience.

1.1.5. Professionals must examine and evaluate patients in physiotherapy practice in order to plan and implement appropriate treatment interventions.

1.1.6. Professionals shall not leave tasks that require professional skills, knowledge, and judgement to be done by incompetent coworkers.

1.1.7. Professionals must continue to improve their knowledge and maintain their professional competence.

1.1.8. Professionals must refer the patient to the competent practitioners and specialists whenever necessary and are not permitted to receive any gain for this referral.

1.1.9. Professionals must supervise the performance of their employees or assistants thoroughly in order to make sure that their performance is in accordance with professional and ethical guidelines. 
1.1.10. Professionals must provide the required facilities to manage emergencies that may occur during patient treatment, and must have sufficient knowledge to act in such cases. They are also obliged to promptly provide further medical interventions to treat the emergency medical condition.

Axis 2: Respect for the patient's privacy, confidentiality, and preferences

1.2.1. Professionals are obliged to maintain the confidentiality of the patient's and shall not disclose medical or personal patient information to others, except upon the request of judicial authorities.

1.2.2. Professionals must provide patients with their medical records upon request.

1.2.3. Professionals must be aware that patient information, including images, should not be shared on social media.

1.2.4. Professionals are obliged to respect patients' privacy and refrain from simultaneous physical ex amination of multiple patients. Patients should be dressed appropriately during the examination and the interventions should be done by a same-sex professional as much as circumstances permit.

1.2.5. Professionals must be aware that when the patient's information needs to be disclosed to a third party, this can only be done with the authorisation of the patient or the surrogate decision-maker.

1.2.6. Professionals are committed to respect the patients' rights to information, self-determination, and decision-making, and to ensure their informed consent to the treatment or the intervention prior to its implementation.

Axis 3: Honesty and veracity

1.3.1. Professionals are obliged to honestly provide information about the nature of their services to patients and colleagues who need to make decisions about utilising them.

1.3.2. Professionals have the right to advertise their services, but they shall not use emotional, unfair, misleading, or deceptive claims and statements.

1.3.3. Professionals are obliged to present their academic degree and licence correctly, and shall not use titles that do not correspond to their training and competency status.

1.3.4. Professionals should not use their professional or business affiliations in a way that restricts service delivery or misleads others.

1.3.5. Professionals have a responsibility to ensure that patients understand the nature of the services provided and, in particular, the estimated costs before the service is provided to them.

1.3.6. Professionals are required to record and maintain accurate and sufficient records and documents in the field of patient assessment and provided services, based on specialised and legal standards and needs.

1.3.7. Professionals can provide the patient with their predictions about the disease and its treatment process, but shall not give false information or guarantees about the efficacy of the service.

1.3.8. Professionals are required to inform the patient about the occurrence of an error or injury to the patient.

Axis 4: Compassion and empathy

1.4.1. Professionals shall treat patients with empathy and compassion.

1.4.2. Professionals are obliged to refrain from interventions and procedures that are solely done to prevent patients' complaints.

1.4.3. Professionals are obliged to do their best to empathise with patients and avoid indifference or loss of self-control and becoming emotionally overwhelmed.
1.4.4. Professionals are obliged to communicate any error causing harm to the patient, while apologising and explaining the compensatory measures they have taken.

1.4.5. Professionals are obliged to take measures to prevent the future recurrence of errors and reduce the extent of the harm that the error has caused and communicate it to the patient.

1.4.6. Professionals are obliged to communicate the error to the patient proxy when the patient lacks decision-making capacity, including in the case of minors, patients with intellectual disability, and patients with decreased consciousness.

\section{Chapter 2: Equity and justice}

2.1. Professionals are required to deliver care to all individuals seeking rehabilitation services, regardless of age, sex, race, colour, nationality, religion, faith, moral beliefs, personal preferences, political beliefs, disability, and health status.

2.2. Professionals are obliged to schedule patients fairly

2.3. Professionals are obliged to ensure that the fees being charged for providing care are reasonable and fair and based on legally approved tariffs.

2.4. Professionals are not entitled to a fee for services that are not provided.

2.5. The provision of specialised services should be commensurate with the needs of patients and without any discrimination.

2.6. Justice must be promoted in human and financial resource allocation, and in cases of limited resources, it is necessary to decide according to the priorities approved by the clinical ethics committees of medical universities or the Iranian Physiotherapy Association.

Chapter 3: Primacy of patient interests and non-maleficence

3.1. Professionals are obliged to treat patients with courtesy and to refrain from offensive behaviour.

3.2. Professionals are obliged to respect patients' time and prioritise the patient's interests.

3.3. Professionals are obliged to take sufficient care and caution to avoid injury to patients.

3.4. Professionals are obliged to take the precautions to avoid injury to patients during treatment procedures.

3.5. Professionals are obliged to serve the interests of the patient while providing care.

3.6. Professionals do not have the right to provide services that are not necessary for the patient.

\section{Chapter 4: Social responsibility of professionals}

4.1. Professionals are obliged to be aware of and act on the rights and responsi bilities they have towards the public, society, colleagues, and their profession.

4.2. Professionals are obliged to contribute to public education programmes and the promotion of public knowledge. 


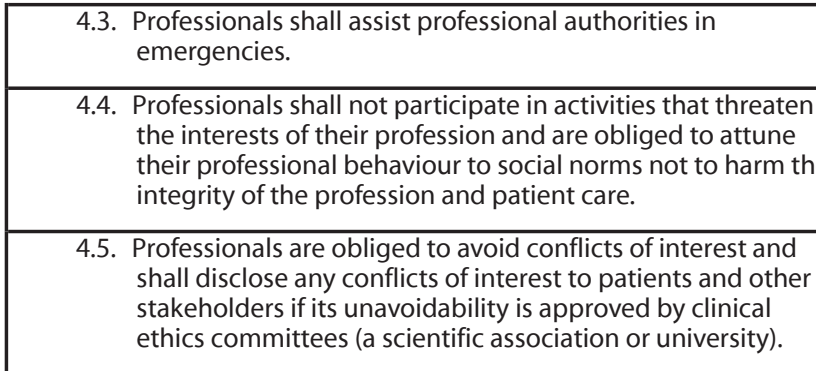

\section{Chapter 5: Ethics in professional relations}

5.1. Professionals are obliged to demonstrate respect while communicating with their colleagues.

5.2. Professionals are obliged to show respect, courtesy, and humility towards faculty members.

5.3. Professionals are obliged to treat students and young colleagues with dignity.

5.4. Professionals are required to respect the administrative hierarchy in service provider organisations.

5.5. As it is essential to maintain the public's trust in the profession of physiotherapy, professionals are obliged not to disclose the scientific and technical errors of their colleagues to patients and to avoid communicating prejudice towards and distrust of their colleagues.

5.6. Professionals are obliged to respectfully communicate colleagues' errors to them and support them in providing information about the error to the patient or their proxy.

5.7. Professionals are obliged to inform the competent authorities when the colleagues involved in the error are not willing to communicate it to the patient.

\section{Chapter 6: Compliance with social norms and regulatory laws}

6.1. Professionals are obliged to be aware of and comply with the ethical rules and national laws governing their profession.

6.2. When regulations are deemed to be in conflict with the moral values held by professionals, the conflict shall be resolved through official institutions and scientific associations.

6.3. Professionals shall not engage in unethical or illegal practices.

6.4. Professionals have the right to refuse to provide services that involve illegal actions.

6.5. Professionals should be aware that they will be subject to disciplinary interventions by ethics committees or legal authorities when they do not comply with ethical or legal rules.

\section{Section 2: Research ethics in physiotherapy}

Chapter 1: General considerations - contributions to research, planning, and promotion of the profession

1.1. Professionals shall cooperate and participate in research activities to improve the quality of the provided services

1.2. Researchers are obliged to submit the research proposal of a clinical trial in accordance with the relevant guidelines.

1.3. Researchers are obliged not to inappropriately use the ideas of others in proposing a research project.

1.4. Researchers are required to disclose the research sponsors and any form of conflict of interest.

1.5. Researchers are obliged to make the results of their research accessible in order to improve the profession, while respecting the rights and interests of all research stakeholders.
1.6. Researchers are obliged to follow the national research ethical guidelines before, during, and after conducting research. They shall also adhere to the principles of publishing ethics and the national guidelines when disseminating research findings.

Chapter 2: Specific considerations for different stages of research

Axis 1: Before conducting research

2.1.1. Researchers are obliged to describe the design and performance of the research study according to a specified protocol and submit it to the relevant scientific committee and an approved research ethics committee before the study begins. Research conducted in the private sector is also subject to this Guideline.

2.1.2. Researchers are obliged to strictly adhere to the approved research protocol. Following approval, changes to the research protocol shall be reviewed and approved by the relevant research committee and research ethics committee.

2.1.3. Researchers are obliged to ensure that the risk of injury to research participants is minimised in the research design.

2.1.4. Researchers shall not inflict harm and injury on research participants or restrict their autonomy for the reason of benefiting society or advancing science.

2.1.5. Necessary measures must be implemented in health-related research to prevent, diagnose, treat, and compensate injuries to research participants before conducting the research.

2.1.6. In research involving patients as participants, the benefits shall outweigh the risks. The relevant research ethics committee has the authority to determine this.

2.1.7. In research involving healthy participants, the acceptable harm shall not be greater than that ordinarily encountered in daily life. In identifying the risks encountered in daily life, the risks that participants confront due to their job, age, time, and place are not taken into account. to patients and to avoid communicating prejudice towards and distrust of their colleagues.

2.1.8. The practicality, simplicity, convenience, expediency, and economical value of the research cannot be a justification for exposing the participants to additional risk through the research. information about the error to the patient or their proxy.

2.1.9. If the research involves increased risk of harm to participants belonging to socioeconomical disadvantaged groups, the research ethics committee must ensure that the participants understand research harms.

2.1.10. Involving research participants in the research without disclosing relevant information is forbidden, unless the study participants have knowingly waived their right to information.

2.1.11. Researchers are obliged to obtain informed consent without any coercion, threats, undue influence, or seduction; otherwise, the consent obtained is invalid and is not legally binding.

2.1.12. If the researcher realises that the participants are facing a serious health threat during the research, he or she is obliged to terminate the research and initiate an appropriate intervention to eliminate the threat.

2.1.13. Research involving vulnerable groups (children, prisoners, prisoners of war, refugees, the intellectually disabled, and the mentally ill) is prohibited, unless it benefits the members of that group.

2.1.14. Vulnerable groups, especially the disabled and elderly, shall not be included in the research population as a preferred class due to their particular circumstances, such as availability, and on the other hand, they shall not be deprived of the benefits of participation in research.

2.1.15. When the disabled and elderly who have limitations in terms of transportation, are the subjects of research, researchers should, as far as possible, approach them in their living quarters to collect data. 
2.1.16. The research methods in use should not be in conflict with the religious and cultural norms of the community.

Axis 2: During the conduct of the research

2.2.1. Researchers are obliged to explicitly disclose any conflicts of interest, especially when they arise from research funding.

2.2.2. The reason for participant selection must be approved by the research ethics committee, when the researcher, organisationally or academically, is in a higher position than the participants, leading to the possibility of coercion of research participants and calling into question the validity of the informed consent.

2.2.3. Researchers are required to explain the method and purpose of the research, potential harms, benefits, and the nature and duration of the research to the extent required by participants, answer their questions properly, and subsequently mention these in the consent form.

2.2.4. It is the responsibility of the researcher to ensure that the participants understand the provided information. In cases where another person provides the information to the participants, the researcher is not disclaimed.

2.2.5. If, in the opinion of the researcher, providing some information to the participants in the research study can leads to distortions in the results, any withholding of information must be approved by the research ethics committee, and the researcher must explain formally how they will inform the participants subsequently.

2.2.6. In clinical trials that have a case-control design, participants shall be informed that they may be randomly assigned to either a control or a placebo group.

2.2.7. In cases where participants in the study receive a placebo treatment and are unaware of the type of treatment (drug), the researcher should make arrangements such that, if necessary, information about the treatment (drug) can be made available to the participants or their physician.

2.2.8. Human research participants should know that they can leave the research study at any time, without having to explain to the researcher the reason for their unwillingness to cooperate.

2.2.9. The participant shall be informed about and supported to manage the adverse consequences of withdrawal from the study.

2.2.10. Researchers are obliged to consider information about the participants as 'secret' and will be kept confidential. They shall inform the participant in advance if there is a limitation on confidentiality.

2.2.11. When research involves vulnerable groups (minors, the mentally retarded, people suffering from dementia, and psychiatric patients), in accordance with article 2.1.13, approval by the ethics committee is required, and the written consent of the legal guardian shall be obtained.

2.2.12. If the research participant does not have dementia or psychotic symptoms at the beginning of the study and develops these conditions during the research, his/her prior consent is invalid, and written consent must be obtained from his/her legal guardian.

2.2.13. Participants who, at the beginning of the research process, were psychotic or under the legal age, shall give written consent if their capacity to consent is restored or acquired during the research, and the prior consent from the legal proxy will no longer be valid.

Third axis: After conducting the research

2.3.1. Any physical damage or financial loss that is imposed on the participants through the research shall be compensated according to the existing laws.

2.3.2. All rights of research stakeholders (participants, researchers, and the funding organisation), including their intellectual properties, shall be protected while publishing or reporting the findings of the research.
2.3.3. Researchers are obliged to inform beneficiaries about the results of the research.

2.3.4. Researchers are obliged to inform participants if a disease or defect is diagnosed in them through the research and to help treat them as much as possible.

2.3.5. While publishing the research results as scientific articles, researchers are required to adhere to the standards of research publication. In particular, the authorship of the manuscript should be carefully considered so that only those who meet them be identified as the author(a) of the article.

2.3.6. Researchers are required to report the personal information of the participants anonymously when publishing the research results, and participants shall be informed and give consent if it is necessary to mention the identifying information.

\section{Section 3: Ethics in physiotherapy education}

\section{Chapter 1: Ethics guide for student education}

Axis 1: making efforts to improve students' knowledge

1.1.1. Professors are obliged to do their best to advance students' knowledge.

1.1.2. Professors are obliged to become familiar with the principles of education as well as modern teaching methods and to use the appropriate teaching methods to achieve the educational goals.

1.1.3. Professors are obliged to have sufficient mastery of the educational content and to ensure that the content provided is accurate, up-to-date, and relevant to the objectives of the course.

1.1.4. Professors are obliged to make every effort to improve their academic proficiency and update their knowledge.

1.1.5. Professors are obliged to refrain from commenting on a question if they do not know the answer and to refer the student to usable resources and references.

1.1.6. Professors are required to use valid principles and methods of evaluation (especially in terms of predictability and transparency).

1.1.7. Professors are required to use a variety of motivational methods and to try to prioritise incentive methods over punitive ones.

1.1.8. Professors are obliged to allocate sufficient time to solve students' educational problems.

Axis 2: Ethical guidelines for clinical education

1.2.1. As the professor is a role model for students, they are obliged to observe the ethics of patient care during clinical education.

1.2.2. Professors are obliged to ensure that patients know members of the healthcare team and their professional status, as well as to teach students to introduce themselves and ask permission while examining a patient.

1.2.3. Professors are obliged to ensure that the educational process does not deprive patients of appropriate and timely treatment.

1.2.4. Professors are obliged to accept students' feedback on possible errors in the process of diagnosis, treatment, and clinical education, and to take appropriate measures to protect the patient's rights, while avoiding any negative effects on student-patient interactions. 


\begin{tabular}{|c|c|}
\hline \multicolumn{2}{|c|}{ Axis 3: Adherence to cultural and social norms } \\
\hline 1.3 .1$. & $\begin{array}{l}\text { Professors are obliged to educate and evaluate students } \\
\text { fairly, impartially, and without discrimination. }\end{array}$ \\
\hline 1.3 .2 & $\begin{array}{l}\text { Professors are obliged to avoid romantic relationships with } \\
\text { students as long as there is a direct educational } \\
\text { relationship. }\end{array}$ \\
\hline 1.3 .3$. & $\begin{array}{l}\text { Professors shall obey the rules of confidentiality and refrain } \\
\text { from disclosing the personal information of students. }\end{array}$ \\
\hline 1.3.4. & $\begin{array}{l}\text { Professors are obliged not to ruin the self-esteem, } \\
\text { personality, and dignity of the students while interacting } \\
\text { with them and to avoid behaviours that can degrade and } \\
\text { drop the self-esteem of students. }\end{array}$ \\
\hline 1.3.5. & $\begin{array}{l}\text { Professors are obligated to maintain discipline and } \\
\text { punctuality and to value students' time. }\end{array}$ \\
\hline 1.3.6. & $\begin{array}{l}\text { Professors have a duty to treat students with empathy and } \\
\text { benevolence and to strive for their moral growth and } \\
\text { development. }\end{array}$ \\
\hline \multicolumn{2}{|r|}{$\begin{array}{l}\text { Chapter 2: Ethics guide to respecting the rights of colleagues, } \\
\text { institutions, and the profession }\end{array}$} \\
\hline 2.1. $\begin{array}{r}\mathrm{P} \\
\mathrm{t} \\
\mathrm{e}\end{array}$ & $\begin{array}{l}\text { Professors are obliged to respect the status and dignity of } \\
\text { their colleagues and cooperate with them in developing and } \\
\text { empowering students. }\end{array}$ \\
\hline $\begin{aligned} 2.2 . & P \\
\mathrm{e} & \\
\text { ir } & \end{aligned}$ & $\begin{array}{l}\text { Professors shall be aware of, respect, and adhere to the } \\
\text { educational goals, policies, and standards of the educational } \\
\text { institution. }\end{array}$ \\
\hline $\begin{aligned} & 2.3 . P \\
& d\end{aligned}$ & $\begin{array}{l}\text { Professors must pay attention to professional commitments } \\
\text { during clinical teaching. }\end{array}$ \\
\hline 2.4. $\mathrm{P}$ & $\begin{array}{l}\text { Professors are required to participate in continuing } \\
\text { professional education, as required. }\end{array}$ \\
\hline \multicolumn{2}{|c|}{ Chapter 3: Ethical guidelines for students } \\
\hline \multicolumn{2}{|c|}{ Axis 1: Striving for the proper use of knowledge } \\
\hline \begin{tabular}{r|r}
3.1 .1 .5 \\
$t$ \\
$t$
\end{tabular} & $\begin{array}{l}\text { Students are obliged to respect the scientific expertise of } \\
\text { the professor, pay attention to his/her teaching, and strive for } \\
\text { the optimal use of knowledge. }\end{array}$ \\
\hline 3.1.2. & $\begin{array}{l}\text { Students are required to observe discipline and punctuality } \\
\text { in the educational process and in educational } \\
\text { environments. }\end{array}$ \\
\hline \multicolumn{2}{|c|}{$\begin{array}{l}\text { 3.1.3. Students are obliged to complete assignments carefully and } \\
\text { turn them in on time. }\end{array}$} \\
\hline $\begin{array}{r}\text { 3.1.4. St } \\
\mathrm{p} \\
\mathrm{t}\end{array}$ & $\begin{array}{l}\text { tudents are obliged to actively participate in the education } \\
\text { process, to strive to improve their academic proficiency, and } \\
\text { to update their knowledge. }\end{array}$ \\
\hline \multicolumn{2}{|c|}{ Axis 2: Ethical guidelines for students during clinical training } \\
\hline \multicolumn{2}{|c|}{$\begin{array}{l}\text { 3.2.1. Students are obliged to observe the ethics of patient care } \\
\text { during clinical education. }\end{array}$} \\
\hline \multicolumn{2}{|r|}{$\begin{array}{l}\text { 3.2.2. Students shall introduce themselves prior to examining the } \\
\text { patients and seek permission from them. }\end{array}$} \\
\hline \multicolumn{2}{|c|}{$\begin{array}{l}\text { 3.2.3. Students are obliged to refrain from engaging in medical } \\
\text { interventions in which they have not received sufficient } \\
\text { training or acquired the needed skills except in the presence } \\
\text { of the professors and under their direct supervision. }\end{array}$} \\
\hline 3.2.4. S & $\begin{array}{l}\text { Students are obligated to report any errors that might cause } \\
\text { harm.to professors as soon as possible }\end{array}$ \\
\hline 3.2.5. S & $\begin{array}{l}\text { Students shall provide appropriate feedback to the professor } \\
\text { in cases where there is a strong possibility of an error having } \\
\text { been made by the professor in the patient's diagnosis or } \\
\text { treatment. }\end{array}$ \\
\hline \multicolumn{2}{|c|}{ Axis 3: Adherence to cultural and social norms } \\
\hline 3.3.1. $\mathrm{S}$ & $\begin{array}{l}\text { Students are obliged to treat their professors fairly and } \\
\text { impartially while evaluating and providing them with } \\
\text { feedback. }\end{array}$ \\
\hline
\end{tabular}

3.3.2. Students are obliged to demonstrate respect, courtesy, and humility in communication with the professors.

3.3.3. Students are obligated to refrain from romantic relationships with the professors as long as there is a direct educational relationship.

\section{Discussion}

Professional codes of ethics are necessary for several reasons. They can clarify moral concerns or dilemmas and stimulate self-regulation among members of the profession, educate and offer direction on ethical decision-making and behaviour, promote public responsibility, and endorse societal expectations (14). The healthcare professions in developing countries are encouraged to develop their own codes of ethics (15). Despite considerable efforts to develop national codes of ethics in Iran (16), much still remains to be done across all healthcare professions. However, a more important responsibility of the concerned authorities is to plan to familiarise healthcare professionals with the developed guidelines (17) and take the necessary steps to implement them.

Though it comprises universal values and elements of common morality, medical professionalism has been shown to be contextually sensitive (18). The aim of this project was to achieve a general consensus on the draft ethical guidelines, culturally adapted for physiotherapists in Iran, which could be used to develop official national guidelines endorsed by the authorities, such as the Islamic Republic of Iran Medical Council (IRIMC), Iranian Physiotherapy Association, or the Ethics Supreme Council of the Ministry of Health and Medical Education. At the end of the three-stage process described above, 134 items were included in the final code of conduct for practitioners, researchers, instructors, and students of physiotherapy.

The main ethical considerations in providing physiotherapy services were 'respect for patient rights and human dignity' (including 'providing high-quality care based on scientific standards', 'respect for patients' privacy and confidentiality', 'honesty and veracity', and 'compassion and empathy'), equity and justice, the primacy of patient interest, non-maleficence, the social responsibility of professionals, ethics in professional relations, and compliance with social norms and regulatory laws.

The main ethical considerations put forth by experts; contribution to research, promotion of the profession, and specific considerations for different stages of research, which are divided into 'before conducting research', 'during the conduct of the research', and 'after conducting the research'. This portion considered the ethical aspects of conceptualising and designing research as well as processes after the the study is completed, such as publication of the results after the study is completed.

The section on ethics in physiotherapy education proposes ethical guidelines for student education, which is divided into 
'demonstrated efforts to advance students' knowledge', 'ethical guidelines for clinical education', and 'adherence to cultural and social norms'; an ethical guide to respecting the rights of colleagues, institutions, and the profession; and the ethical guidelines for students, which is divided into 'striving for the proper use of knowledge,'ethical guideline for clinical education of students', and 'adherence to cultural and social norms'

Given the universal nature of the professional values embedded in the healthcare delivery system (19), it is to be expected that the code developed in this project is consistent with other professional codes of ethics currently implemented worldwide, particularly codes of ethics for physical therapists, as provided by the WCPT and the APTA.

A closer look at the similarities and differences between codes of ethics for physical therapists developed by international and national physical therapy associations (such as the WCPT and the APTA) and the present guidelines reveals a congruency in the core values, though they are adapted to the particular structure of the Iranian healthcare system and the nation's cultural background, and so include more detailed advice in some areas.

In all three versions considered here (APTA, WCPT, and our version), the foremost principle is respect for the patient's rights and human dignity. The experts who participated in this project insisted more on human dignity than the principle of respect for patients' autonomy, as the emphasis on inherent human dignity is quite strong in Islamic culture. As Sachedina states in his Islamic biomedical ethics book, according to the holy Quran (Q. 17:71), all humankind, whether Muslim or not, is to be accorded the same dignity (20: pp. 180-1). While the APTA and the WCPT mention privacy and confidentiality, we have also assigned several additional codes to the principle of respect for the patient's privacy and confidentiality, and tried to consider different examples of maintaining confidentiality and privacy to close any room for violations in this area, so as to be completely in agreement with the emphasis of Islamic ethics on the value of bodily modesty (21: p. 408).

Additional codes in the present guidelines are also extended along the axes of compassion and empathy, since compassion and mercy are part of the Islamic religious tradition and can promote better care delivery to patients in Muslim societies (20: pp. 25-27). Hence, the present ethical guidelines are well adapted to Iranian cultural norms. Furthermore, the authors have helpful administrative experience in ethics and physiotherapy professional and regulatory bodies as well as scientific research experience in the field of ethical (13) and cultural (22) accreditation of hospitals in Iran.

These six values (Table 2, Section 1) were the ones that the experts believed to be the most important ethical considerations for Iranian physical therapists in the context of their therapeutic practice. Their concern for human dignity, human rights, equity, beneficence, and non-maleficence was widely shared despite some regional and contextual differences. The values emphasised in this study also include the principles of beneficence, non-maleficence, and justice in common with the statement of biomedical ethics by Beauchamp and Childress (23). The ethical concerns expressed by the Iranian experts show much in common with those of other ethicists around the world. This may be due to the influence of bioethics education in Iran over two decades (24). It could also be in accordance with the theory of 'common morality' (25).

On the other hand, the APTA and WCPT codes include a title for responsibility for judgement, which is absent in our guidelines. In the Iranian healthcare system, patients are referred to a physiotherapist only by a specialist medical doctor and therefore the physiotherapist is not directly responsible for diagnosing the disease, maybe the difference would be due to that.

Providing several codes for education, research, and professor-student relationships, besides ethical codes for patient care, is another major difference between our version and the APTA and WCPT versions. The reason is that public health centres in Iran are often a subset of larger medicaleducational-research centres, and therefore patients referred to public clinics are evaluated, treated, and studied by both professors and students. This consideration is also echoed in other codes of professional ethics compiled in Iran, such as the Iranian Society of Asthma and Allergy Codes of Professional Ethics (26), the Code of Ethics for Iranian Nurses (27), and the Guideline for Professional Conduct in Medical Practice (28).

Healthcare professionals are responsible not only to their individual patients, but also to society (29). This is reflected in the ethical code developed through this project in consultation with, and by achieving consensus among, experts. Physiotherapist-patient relationships, which are an important issue in debates on ethics and professional codes $(30,31)$, are also covered in our guidelines. From an organisational ethics perspective, respect for and compliance with social norms, ethics, and laws is the foundation of ethical behaviour. As Spencer and colleagues have noted, ethics programmes are distinct from compliance programmes in healthcare organisations, and compliance with the law is the minimum level of ethics that healthcare organisations should aim to meet (32: pp. 3-15.). This issue is well addressed through this study.

The most important limitation of this study, in terms of replicability, was the time-consuming modified Delphi method. Maintaining anonymity, comparing and reconciling the comments from all experts, and encouraging them to respond required considerable investments of time and management efforts. All healthcare professionals are at risk of being placed in situations where institutional constraints may conflict with the practitioner's perception of the right 
thing to do (33). In addition, in rehabilitation services, practitioners may face different and more challenging ethical issues compared to other medical services, because their patients are often managed by a multidisciplinary team rather than a single doctor (34: pp. 8012). Failure to explore the views of patients as well as healthcare providers from the private sector is also among the limitations of this research. This aspect requires further research to improve the validity of the developed code.

\section{Conclusion}

The code of ethical conduct for physiotherapists developed with the methods reported here appears to be necessary and is suitable to support patients, researchers, students, and teachers in the field of physical therapy. This code, in addition to supporting best practices, is compliant with Iranian culture and current legislative requirements. We are therefore hopeful that this code can be implemented to appropriately support education, research, and practice in physical therapy, although it must be said that more work needs to be done to improve the practical guidelines for physiotherapists to help them to better navigate clinical cases. Although this project was a part of a national physiotherapy curriculum revision conducted by the ViceChancellery for Education, Ministry of Health and Medical Education (MOHME), it is not a national code of conduct yet. However, it could be used as a draft to develop official national guidelines by authorities such as the IRIMC, the Iranian Physiotherapy Association, or the Ethics Supreme Council of the Ministry of Health and Medical Education.

\section{Acknowledgements}

This study was financially supported by the University of Social Welfare and Rehabilitation Sciences, Tehran, Iran. The authors also thank all the participants in the focus group discussion and the modified Delphi procedure, and K. Shashok (AuthorAID in the Eastern Mediterranean) for improving the English writing of the manuscript, and Dr. Maryam Ansari for editing the tables.

\section{*Note}

The Persian text of these guidelines is available from:

https://dorsa.sums.ac.ir/Dorsapax/userfiles/Sub78/ Departments/Physical-Therapy/Published/Ethics-ForPhysical-Therapists.pdf

\section{Conflict of interests: None declared}

\section{References}

1. Cruess $\mathrm{RL}$, Cruess $\mathrm{SR}$, Steinert $\mathrm{Y}$, editors. Teaching medical professionalism: supporting the development of a professional identity. 2nd ed. Cambridge: Cambridge University Press; 2016.

2. Triezenberg HL. The identification of ethical issues in physical therapy practice. Phys Ther. 1996 Oct 1;76(10):1097-107.

3. Delany CM, Edwards I, Jensen GM, Skinner E. Closing the gap between ethics knowledge and practice through active engagement: an applied model of physical therapy ethics. Phys Ther. 2010 Jul 1;90(7):1068-78.

4. Swisher LL. A retrospective analysis of ethics knowledge in physical therapy (1970-2000). Phys Ther. 2002;82:692-706
5. Edwards I, Delany CM, Townsend AF, Swisher LL. New perspectives on the theory of justice: implications for physical therapy ethics and clinical practice. Phys Ther. 2011 Nov 1;91(11):1642-52.

6. The American Physical Therapy Association (APTA). Code of ethics for the physical therapist. APTA; 2020 Aug [cited 2019 May 14]. Available from: http://www.apta.org/uploadedFiles/APTAorg/About_Us/ Policies/Ethics/CodeofEthics.pdf.

7. The Physiotherapy Board of Australia. Code of conduct for registered health practitioners. PBA; 2014 Mar [cited 2019 May 14]. Available from: https://www.physiotherapyboard.gov.au/codes-guidelines/ code-of-conduct.aspx.

8. The World Confederation for Physical Therapy (WCPT). WCPT declaration of principle on ethical principles. WCPT; 2007 [cited 2019 May 14]. Available from: https://www.wcpt.org/sites/wcpt.org/files/ files/WCPT-DoP-Ethical_Principles-Aug07.pdf.

9. Papadopoulos I, Tilki M, Taylor G. Transcultural care: a guide for health care professionals. Quay Books; 1998.

10. Bialocerkowski A, Wells C, Grimmer-Somers K. Teaching physiotherapy skills in culturally-diverse classes. BMC Med Educ. 2011 Dec;11(1):34.

11. Swisher LL, Hiller P. The revised APTA code of ethics for the physical therapist and standards of ethical conduct for the physical therapist assistant: theory, purpose, process, and significance. Phys Ther. 2010; 90(5):803-24.

12. Mohamadi M, Mahmoodian H, Ajdari N. Comparison of world confederation's code of ethics for physical therapy to Islamic culture principles. Sadra Medical Sciences Journal. 2017 Mar 28: 2017; 5(2): 111-118.

13. Enjoo SA, Amini M, Tabei SZ, Mahbudi A, Kavosi Z, Saber M. The main indicators for Iranian hospital ethical accreditation. JAMP. 2015 Jul; 3(3): 117.

14. Swisher LL, Hiller P; APTA Task Force to Revise the Core Ethics Documents. The revised APTA code of ethics for the physical therapist and standards of ethical conduct for the physical therapist assistant: theory, purpose, process, and significance. Phys Ther. 2010 May 1;90(5):803-24.

15. Hameed DM, Oleiwi SR, Aldakheel AH. Evaluation of nurses' commitment to ethical codes in patients care. Indian J Forensic Med Toxicol. 2018;12(4):160-4

16. Shahriari M, Mohammadi E, Fooladi MM, Abbaszadeh A, Bahrami M. Proposing codes of ethics for Iranian nurses: a mixed methods study. $J$ Mix Methods Res. 2016 Oct;10(4):352-66.

17. Subramanian T, Mathai AK, Kumar N. Knowledge and practice of clinical ethics among healthcare providers in a government hospital, Chennai. Indian J Med Ethics. 2013 Apr-Jun;(10)2:96-100.

18. Al-Eraky MM, Chandratilake M. How medical professionalism is conceptualised in Arabian context: a validation study. Med Teach. 2012 Apr 1;34 Suppl 1:S90-5.

19. Al-Rumayyan A, Van Mook WN, Magzoub ME, Al-Eraky MM, Ferwana M, Khan MA, Dolmans D. Medical professionalism frameworks across non-Western cultures: a narrative overview. Med Teach. 2017 Mar 16;39 Suppl 1:S8-14.

20. Sachedina A. Islamic biomedical ethics: principles and application. Oxford: Oxford University Press; 2009. Pp. 180-1.

21. Daar AS, Bakdash T, Khitamy AB. Islamic bioethics. In: Singer PA, ViensAM, editors. The Cambridge textbook of bioethics. Cambridge University Press; 2008.

22. Enjoo SA, Kavosi Z, Tabei SZ, Mohagheghzadeh A. Developing a tool for cultural accreditation (Shafi project) in hospitals of Shiraz University of Medical Sciences. Iranian J Med Ethics Hist Med. 2017 Apr 10;10(1):165-81.

23. Beauchamp TL, Childress JF. Principles of biomedical ethics. USA: Oxford University Press; 7th ed. 2013.

24. Kiani M, Bazmi S. Teaching medical ethics in Iran: a quantitative study. Journal of Medical Education. 2016 Dec 7;15(3): e105521. 124135.

25. Beauchamp TL. A defense of the common morality. Kennedy Inst Ethics J. 2003;13(3):259-74.

26. Shamsi-Gooshki E, Pishkuhi MA, Mousavi MS, Raoofi A, Fazlollahi MR, Parsapour A, Moin M. Iranian Society of Asthma and Allergy Codes of Professional Ethics. Iran J Allergy, Asthma Immunol. 2020 Apr 16;19(2): 117-131.

27. Sanjari M, Zahedi F, Aalaa M, Peimani M, Parsapoor A, Cheraghi MA, Mirzabeigi G, Larijani B. Code of ethics for Iranian nurses. Iranian J Med Ethics Hist Med. 2011 Dec 10;5(1):17-28.

28. Tehrani SS, Nayeri F, Parsapoor A, Jafarian A, Labaf A, Mirzazadeh A, Kouchak HE, Shahi F, Ghasemzadeh N, Asghari F. Development of the first guideline for professional conduct in medical practice in Iran. 
AIM Journal. 2017 Jan 1;20(1):12-15

29. Cruess SR, Cruess RL. Professionalism: a contract between medicine and society. CMAJ. 2000 Mar 7;162(5):668-9.

30. Sharma $S$. The deteriorating patient-physician relationship in India: is it time to look within? Indian J Med Ethics. 2019 Sep 11:1-2.

31. Gopichandran V, Chetlapalli SK. Trust in the physician-patient relationship in developing healthcare settings: a quantitative exploration. Indian J Med Ethics. 2015 Jul;12(3):141-8.

32. Spencer EM, Mills AE, Rorty MV, Werhane PH. Organization ethics in health care. Oxford:Oxford University Press; 2000.

33. Green MM, Wicclair MR, Wocial LD, Kondrat A, Mukherjee D. Moral distress in rehabilitation. PM R. $2017 \mathrm{Jul} ; 9(7): 720$.

34. Bliuc RE, Astarastoae V, Stratulat SI. Improving the education in the field of patient autonomy in rehabilitation doctors working with engineers. Proceedings of the MATEC Web of Conferences 2017: vo 112. 08012 http://dx.doi.org/10.1051/matecconf/
DOI:

201711208012 